\title{
Editorial
}

\section{New Perspectives on Integrating Self-Regulated Learning at School}

\author{
Bracha Kramarski, ${ }^{1}$ Annemie Desoete, ${ }^{2}$ Maria Bannert, ${ }^{3}$ \\ Susanne Narciss, ${ }^{4}$ and Nancy Perry ${ }^{5}$ \\ ${ }^{1}$ Department of Education, Bar-Ilan University, 52100 Ramat-Gan, Israel \\ ${ }^{2}$ Department of Experimental Clinical and Health Psychology, Ghent University, Ghent, Belgium \\ ${ }^{3}$ Department of Human-Computer Media, Wuerzburg University, Wuerzburg, Germany \\ ${ }^{4}$ Department of Psychology, Technische Universität Dresden, 01062 Dresden, Germany \\ ${ }^{5}$ Department of Educational \& Counselling Psychology and Special Education, University of British Columbia, Vancouver, BC, Canada
}

Correspondence should be addressed to Bracha Kramarski; bracha.kramarski@biu.ac.il

Received 20 February 2013; Accepted 20 February 2013

Copyright (C) 2013 Bracha Kramarski et al. This is an open access article distributed under the Creative Commons Attribution License, which permits unrestricted use, distribution, and reproduction in any medium, provided the original work is properly cited.

\section{Introduction}

In recent years the role of self-regulated learning (SRL) in education has garnered considerable attention from educators, researchers, and policy makers $[1,2]$. Though there are several SRL models proposing different constructs, they still share basic assumptions about self-regulation in learning [3, 4]. Specifically, SRL is an active process, which relates to "selfgenerated thoughts, feelings, and actions that are planned and cyclically adapted to the attainment of personal goals" [4, p. 14]. Learners are self-regulated to the extent that they are cognitively/metacognitively, motivationally, and behaviorally active participants in their own learning process (e.g., [3-5]).

SRL is an important interdisciplinary competence that leads to improved learning and helps individuals cope with the challenges of life-long learning in a knowledge society [2]. It is widely accepted that SRL has a crucial role in school achievement. Children and young people with higher levels of SRL are more likely to succeed academically than students with low SRL (e.g., [6-8]).

So far, the research supports a few general conclusions: SRL is teachable in the classroom, SRL must be explicitly taught and intensively practiced, and interactive learning environments are effective for implementing SRL instruction (e.g., $[9,10])$. The activities required to promote SRL strategies (including planning, monitoring, and evaluation) are naming the strategy, explaining the what, why, and how, and modeling the strategy's application (e.g., [10-13]). Finally, the teacher's role must include being able to cultivate self-regulated learners. But if teachers are not equipped to self-regulate their own learning, how can they develop SRL in their students? Learners depend on teachers, teaching methods, and learning conditions to acquire SRL (e.g., [6, 14-16]).

This special issue brings together a series of papers on some of the theoretical, methodological, and practical issues in SRL and discusses various new perspectives for integrating it into schools. The issue hopes to add greater depth to the broader subject of the contribution of SRL in schools, by analyzing the features and conditions in schools that can support SRL development in teachers and students in key areas, including the following.

(a) Subjects: mathematics (M. Leidinger and F. Perels; G. Papantoniou et al.; J. Roelle et al.); science (T. J. Cleary and P. Platten; S. Eggert et al.; K. Schmidt et al.), and reading (D. L. Butler et al.).

(b) Ages: primary school (M. Leidinger and F. Perels; J. Roelle et al.), secondary school (K. Schmidt et al.), and high school (T. J. Cleary and P. Platten; S. Eggert et al.). 
(c) Type of prompt: self-questions; (e.g., S. Eggert et al.); relating to different phases (Zimmerman model; M. Leidinger and F. Perels); relating to objects (generic/personal reflection; e.g., K. Schmidt et al.).

(d) Learning materials: problem solving examples (e.g., J. Roelle et al.) focusing on interactive learning environments such as CBLE (I. Glogger et al.), collaborative learning (S. Eggert et al.) for students, and teachers development.

The issue contributes significantly to SRL assessment by exploring ways of evaluating SRL as a dynamic process in real-time situations and by combining different kinds of measures for assessing such processes $[1,5,17,18]$. The articles describe a variety of methodologies such as, using reflective learning journals (e.g., M. Leidinger and F. Perels); observations (D. L. Butler et al.); interviews (e.g., T. J. Cleary and P. Platten); multi-dimensional assessment with a variety of research designs, for example, the quasi-experimental combination of pre-/postcontrol-group design and time series design (e.g., M. Leidinger and F. Perels); case studies (T. J. Cleary and P. Platten), meta-analysis type of literature review (D. C. Moos and A. Ringdal), and path analysis models (G. Papantoniou et al.).

We have divided the issue into two parts with 5 papers in each. Part 1 examines the learner's role while Part 2 examines the teacher's role in integrating SRL in the school.

1.1. Part 1: Studies about the Learner's Role in Integrating SRL at School. (a) M. Leidinger and F. Perels have developed mathematics learning materials based on Zimmerman's selfregulated learning model [4]. The purpose of the materials is to develop core cognitive, metacognitive, and motivational components of self-regulated learning within a natural primary school learning environment. Evaluation of the SRL-training materials is based on a quasi-experimental pre-/postcontrol-group design with a time series design. Intervention was evaluated using a self-regulated learning questionnaire, standardized mathematics test, and process data consisting of structured paper-and-pencil diaries that students recorded for six weeks. The evaluation reveals that when fourth graders (age 9-10) are given these SRL-training materials in regular mathematics lessons, they can maintain their self-reported self-regulated learning activities not only for the 6-week training phase, but for the next year as well. However, fourth graders who did not receive the training materials demonstrated a significant decline in their SRLactivities between the pre- and posttest. Despite several limitations, the study illustrates that self-regulated learning can be integrated at primary schools by asking teachers to use SRL-training materials in their regular mathematics lessons.

(b) J. Roelle et al. examined the use of solved example problems for fostering strategies of self-regulated learning in journal writing. In a quasi-experimental field study, 5th grade students (ages 11-12) were given examples of solved math problems and prompts, either from the start of their journal writing, or after they had written two entries. The results suggested that when fifth grade students are given solved example problems with prompts from the time they start keeping their journals, it can effectively support them in overcoming deficits in their SRL strategies in mathematics.

(c) In a quasi-experimental field study, K. Schmidt et al. investigated the effects of personal-utility reflection prompts in journal writing on 7th grade (ages 13-14) students' learning motivation and comprehension in biology education. Previous research on journal writing, focusing on supporting the application of cognitive and metacognitive strategies in learning journals, has shown that prompting cognitive and metacognitive strategies are not enough to sustain student motivation over time. In order to support student motivation, K. Schmidt et al. used personal-utility prompts, cognitive prompts, and metacognitive prompts in the students' learning journal assignment. The results showed that prompting reflection about the personal relevance of the learning contents in the learning journals strongly influences learning motivation and that these motivational effects were positively correlated to learning outcomes as measured by a curriculum-based comprehension test. Thus journal writing which involves reflection on the utility and value of learning can be effective in supporting student motivation and comprehension in secondary science education.

(d) S. Eggert et al. examined the effect of embedded metacognitive instructions on senior high school students' (age 17) socioscientific decision making in the science classroom. Participants studied either in a cooperative learning setting (COOP), a cooperative learning setting with embedded metacognitive questions (COOP + META), or a nontreatment control group. Results show that the students in both the training conditions outperformed students in the control group regarding both processes of socioscientific decision making. However, students in the COOP + META condition did not outperform students in the COOP condition. The authors discuss these surprising findings and the shortcomings of the study.

(e) T. J. Cleary and P. Platten examined the correspondence between self-regulated learning and academic achievement using case study analysis. Four high school students (9th graders, age 14) received 11 weeks of a self-regulated learning (SRL) intervention, called the Self-Regulation Empowerment Program (SREP), which sought to improve their classroom-based biology exam scores, SRL, and motivated behaviors. This mixed model case study examined the correspondence between shifts in students' strategic, regulated behaviors, and performance on classroom-based biology tests. This multidimensional assessment approach was used to establish convergence among the assessment tools and facilitate interpretation of trends in students' biology test performance relative to their SRL processes.

1.2. Part 2: Studies on the Teacher's Role in Integrating SRL at School. (a) D. C. Moos and A. Ringdal offer a metaanalysis literature review of the teacher's role in promoting SRL in the classroom. They systematically consider the following research questions.

How does the literature endorse SRL in teacher education programs? What does the literature say about the use of 
SRL and different kinds of teachers? How does research that examines self-regulation in the classroom measure SRL? The review concludes with the theoretical, methodological, and practical implications of the studies reviewed.

(b) C. D.-van Ewijk and G. van der Werf investigated teachers' beliefs, knowledge, and behavior in the context of self-regulated learning in primary schools. The authors assessed primary school teachers' knowledge and beliefs regarding two aspects of promoting SRL: strategy instruction and the constructivist learning environment. A randomized sample of forty-seven Dutch teachers' (ages 24-63 years) who taught grade 5 or 6 were selected for the study. The teachers answered open-ended questions regarding their understanding of SRL and on their implementation of SRL in their classrooms. Teachers were found more positive towards a constructivist learning environment than towards SRL (i.e., strategy instruction). However, teacher beliefs towards SRL are the only predictor of teacher behavior. The results show how teacher education can support teachers in learning how to promote SRL effectively to their students.

(c) G. Papantoniou et al. examined the links between effect, self-regulated learning strategy use, and course attainment in the didactics of mathematics (teaching mathematics) subject matter domain, at the School of Early Childhood Education. The sample consisted of 180 student teachers (aged 19-23). Pearson's correlations and path analysis revealed that negative effect was positively related to cognitive interference, whereas positive effect positively influenced the use of almost all the SRL strategies. The only SRL strategy which predicted the didactics of mathematics course attainment was elaboration.

(d) I. Glogger et al. developed and evaluated a computerbased learning environment for teachers: "Assessment of learning strategies in learning journals." Though it is important to train teachers to assess key SRL components such as learning strategies, this area is a somewhat neglected in efforts to support teachers' use of SRL at school. Learning journals can assess learning strategies in line with cyclical process models of self-regulated learning, allowing for rich formative feedback. In light of this, the authors developed a computer-based learning environment (CBLE) for training student teachers (ages 20-26) to assess learning strategies with learning journals. They found high levels of satisfaction, interest, and good usability, as well as satisfactory assessment skills after working with the CBLE.

(e) D. L. Butler et al. investigated what happens when teachers work collaboratively to support self-regulated Learning Through Reading (LTR) in adolescents. They report the findings of a longitudinal project in which secondary school teachers worked collaboratively to support adolescents' selfregulated LTR in subject-discipline classrooms. More specifically, the authors investigated whether and how teachers working within a community of inquiry had mobilized research to shape classroom practice and advance student learning. To link practice changes to student outcomes, they related pre- and postshifts in students' self-regulated LTR for 364 students (grades 7-9) in relation to practices employed by 12 teachers in 20 humanities classrooms.

\section{Final Remarks and Implications for Future Work}

This special issue contributes importantly to enriching the literature on self-regulation in learning for students and teachers in diverse conditions and learning environments. However, more attention needs to be paid to the ability of SRL to meet the diverse learning needs of individual students in mixed ability classrooms. This suggestion concurs with the researchers' proposals for the teaching curriculum to address the often major gaps between students with different intellectual needs trying to learn in the same classroom, such as high achievers and gifted students (e.g., [19]) and students with learning disabilities (e.g., [20]). Future research needs to evaluate the efficacy of adapted SRL prompts in challenging high achievers to acquire a sophisticated understanding of the core curriculum in an advanced learning environment and, equally important, to support the low achievers in monitoring and regulating their learning as well.

And as for teachers, if it is our aim to promote the widespread adoption of SRL in the classroom, then our focus should be on improving teachers' understanding of SRL and on supporting them in developing and adopting self-regulated teaching practices. Our goal should be to empower experienced teachers and student teachers to be self-regulated learners themselves and to in turn cultivate successful self-regulated learners of all achievement levels within their classrooms $[14,21,22]$. To this end, some of the most relevant issues for future research are developing, introducing, and evaluating SRL-training in teacher education programs.

Bracha Kramarski
Annemie Desoete
Maria Bannert
Susanne Narciss
Nancy Perry

\section{References}

[1] M. Boekaerts and E. Cascallar, "How far have we moved toward the integration of theory and practice in self-regulation?" Educational Psychology Review, vol. 18, no. 3, pp. 199-210, 2006.

[2] OECD, PISA 2012. Assessment and Analytical Framework: Mathematics, Reading, Science, Problem Solving and Financial Literacy, OECD, 2013.

[3] P. R. Pintrich, "The role of goal orientation in self-regulated learning," in Handbook of Self-Regulation, M. Boekaerts, P. Pintrich, and M. Zeidner, Eds., pp. 451-502, Academic Press, Orlando, Fla, USA, 2000.

[4] B. Zimmerman, "Attaining self-regulation," in Handbook of SelfRegulation, M. Boekaerts, P. Pintrich, and M. Zeidner, Eds., pp. 13-39, Academic Press, San Diego, Calif, USA, 2000.

[5] P. H. Winne and N. E. Perry, "Measuring self-regulated learning," in Handbook of Self-Regulation, M. Boekaerts, P. Pintrich, and M. Zeidner, Eds., pp. 531-566, Academic Press, Orlando, Fla, USA, 2000.

[6] C. Dignath and G. Büttner, "Components of fostering selfregulated learning among students. A meta-analysis on 
intervention studies at primary and secondary school level," Metacognition and Learning, vol. 3, no. 3, pp. 231-264, 2008.

[7] F. J. Morrison, C. C. Ponitz, and M. M. McClelland, "Selfregulation and academic achievement in the transition to school," in Child Development at the Intersection of Emotion and Cognition, S. D. Calkins and M. A. Bell, Eds., pp. 203-224, American Psychological Association, Washington, DC, USA, 2010.

[8] S. E. Rimm-Kaufman, T. W. Curby, K. J. Grimm, L. Nathanson, and L. L. Brock, "The contribution of children's self-regulation and classroom quality to children's adaptive behaviors in the kindergarten classroom," Developmental Psychology, vol. 45, no. 4, pp. 958-972, 2009.

[9] R. Azevedo and J. G. Cromley, "Does training on self-regulated learning facilitate students' learning with hypermedia?” Journal of Educational Psychology, vol. 96, no. 3, pp. 523-535, 2004.

[10] G. Schraw, K. J. Crippen, and K. Hartley, "Promoting selfregulation in science education: metacognition as part of a broader perspective on learning," Research in Science Education, vol. 36, no. 1-2, pp. 111-139, 2006.

[11] M. Bannert, "Promoting self-regulated learning through prompts," Zeitschrift fur Padagogische Psychologie, vol. 23, no. 2, pp. 139-145, 2009.

[12] B. Kramarski and T. Revach, "The challenge of self-regulated learning in mathematics teachers' professional training," $E d u$ cational Studies in Mathematics, vol. 72, pp. 379-399, 2009.

[13] M. V. J. Veenman, B. H. A. M. Van Hout-Wolters, and P. Afflerbach, "Metacognition and learning: conceptual and methodological considerations," Metacognition and Learning, vol. 1, no. 1, pp. 3-14, 2006.

[14] B. Kramarski and T. Michalsky, "Investigating preservice teachers' professional growth in self-regulated learning environments," Journal of Educational Psychology, vol. 101, no. 1, pp. 161175, 2009.

[15] B. Kramarski and T. Michalsky, "Preparing preservice teachers for self-regulated learning in the context of technological pedagogical content knowledge," Learning and Instruction, vol. 20, no. 5, pp. 434-447, 2010.

[16] N. E. Perry, L. Hutchinson, and C. Thauberger, "Talking about teaching self-regulated learning: scaffolding student teachers' development and use of practices that promote self-regulated learning," International Journal of Educational Research, vol. 47, no. 2, pp. 97-108, 2008.

[17] J. A. Greene and R. Azevedo, "The measurement of learners' self-regulated cognitive and metacognitive processes while using computer-based learning environments," Educational Psychologist, vol. 45, no. 4, pp. 203-209, 2010.

[18] B. J. Zimmerman, "Investigating self-regulation and motivation: historical background, methodological developments, and future prospects," American Educational Research Journal, vol. 45, no. 1, pp. 166-183, 2008.

[19] C. A. Tomlinson, "Quality curriculum and instruction for highly able students," Theory into Practice, vol. 44, no. 2, pp. 160166, 2005.

[20] A. Desoete, H. Roeyers, and A. De Clercq, "Can offline metacognition enhance mathematical problem solving?" Journal of Educational Psychology, vol. 95, no. 1, pp. 188-200, 2003.

[21] J. Randi and L. Corno, "Teacher innovations in self-regulated learning," in Handbook of Self-Regulation, M. Boekaerts, P. R. Pintrich, and M. Zeidner, Eds., pp. 651-685, Academic Press, San Diego, Calif, USA, 2000.
[22] J. Randi and L. Corno, "Theory into practice: a matter of transfer," Theory into Practice, vol. 46, no. 4, pp. 334-342, 2007. 

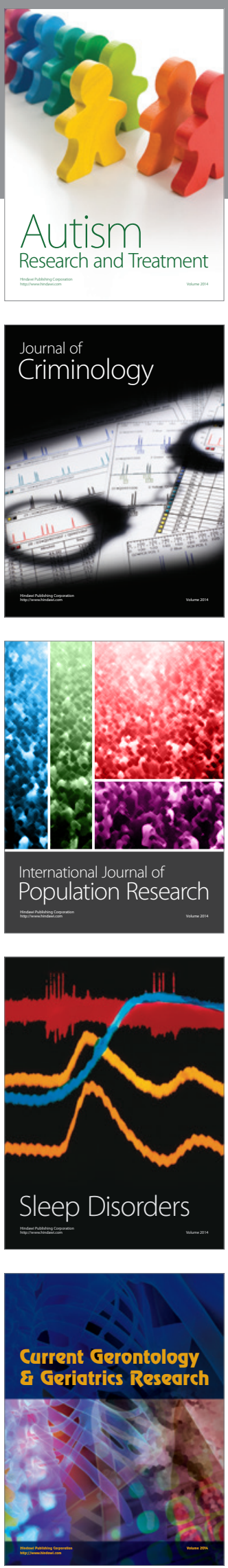
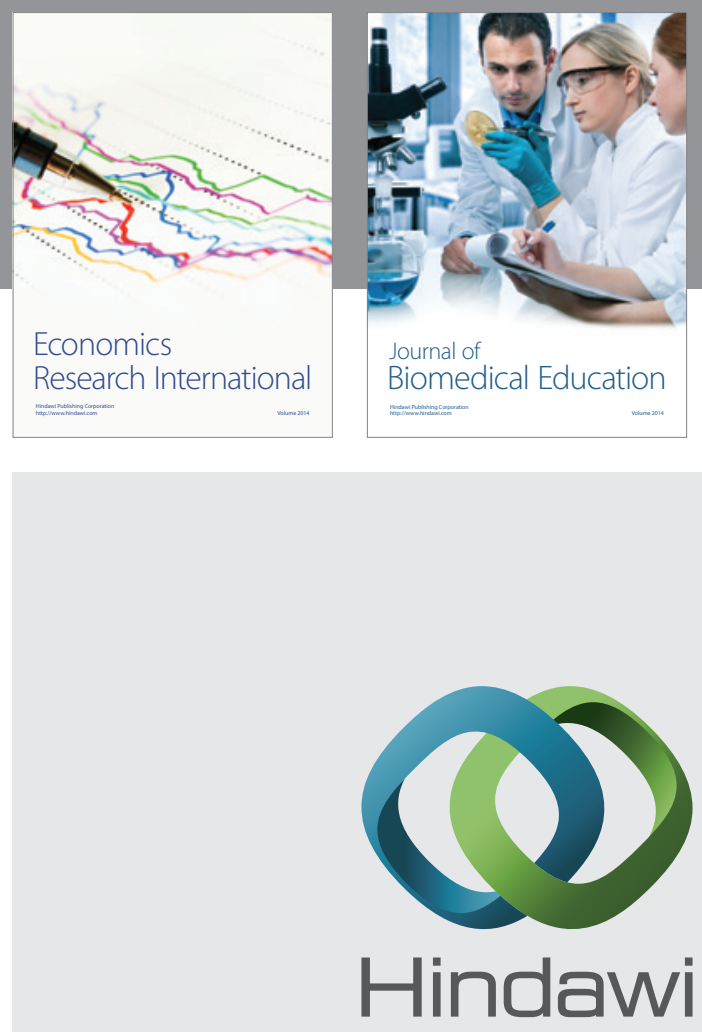

Submit your manuscripts at

http://www.hindawi.com
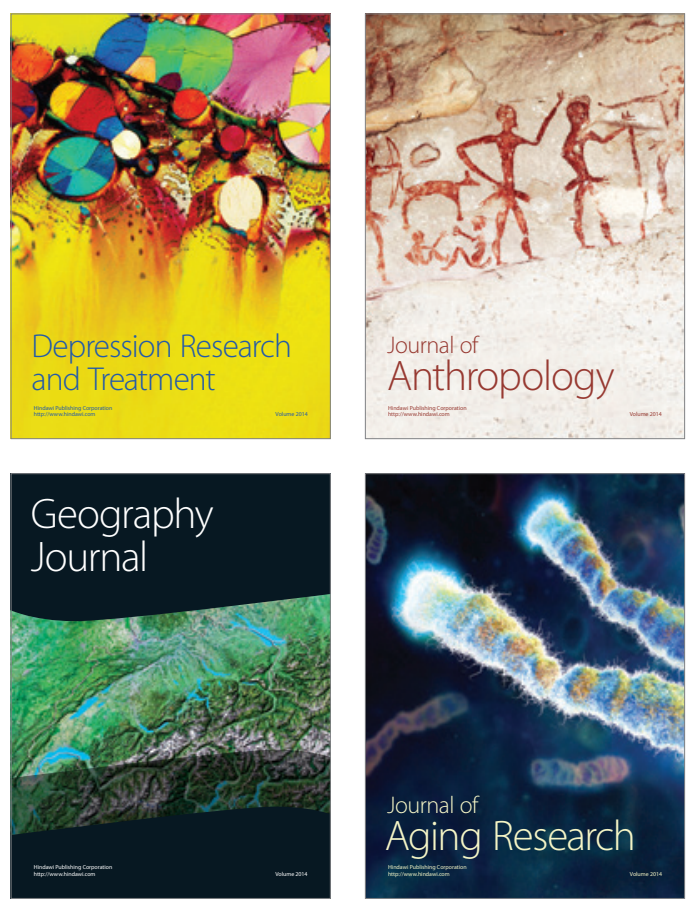
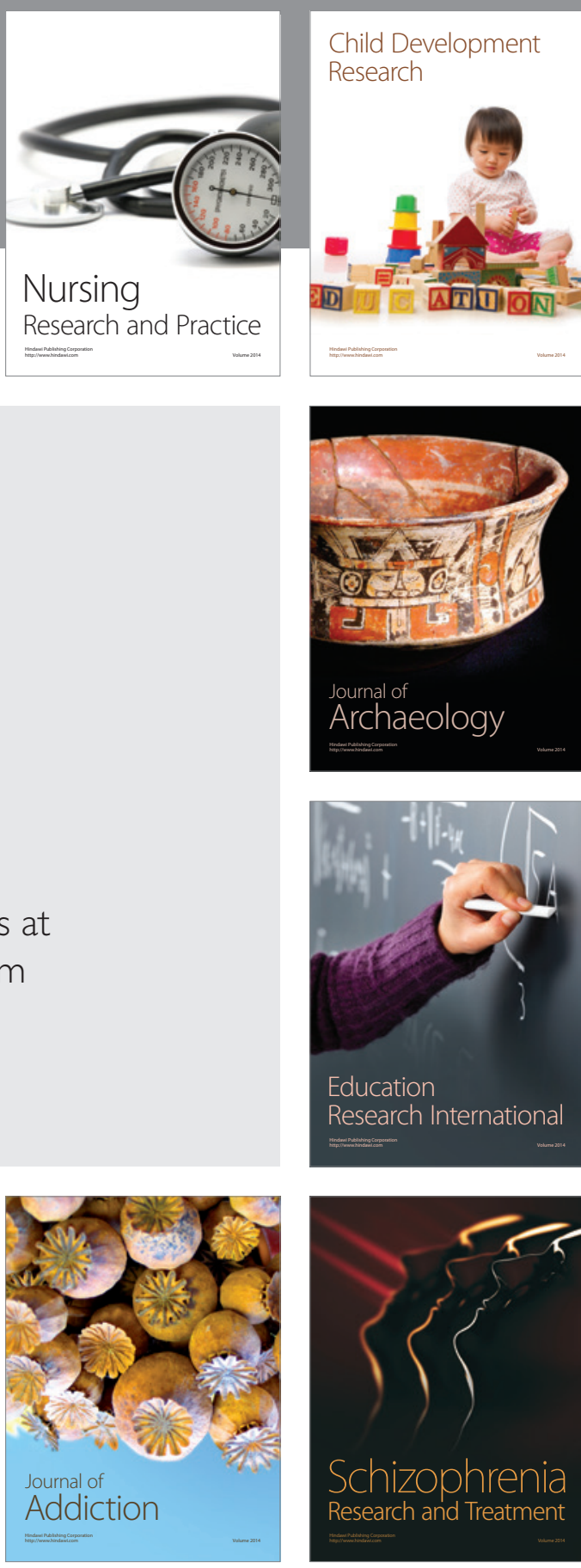

(D)
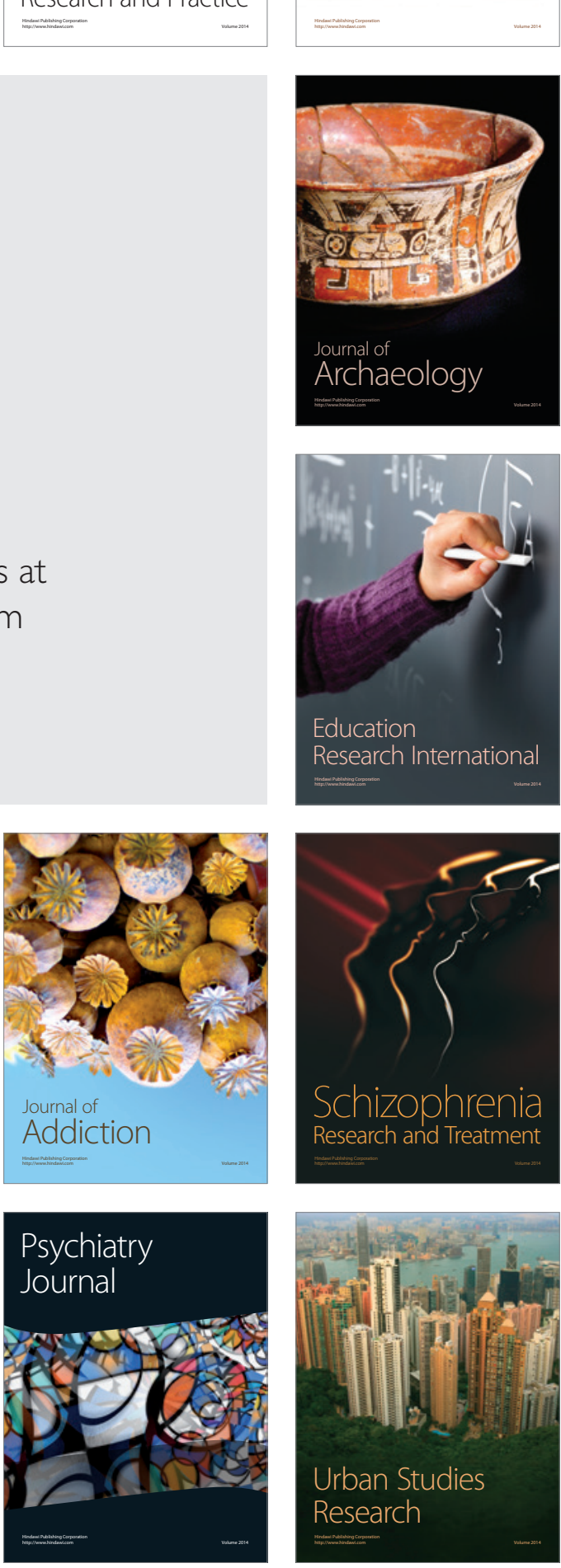